\title{
Discovery of the RNA Synthetic Activity of Glutamate Dehydrogenase and Its Application in Drug Metabolism Research
}

\author{
Godson O. Osuji*, Tassine K. Brown and Sanique M. South
}

CARC, Prairie View A\&M University, P.O. Box 519-2008, Prairie View, Texas 77446, USA

\begin{abstract}
Glutamate dehydrogenase (GHD) synthesizes some RNAs that regulate mRNA abundance in response to the environment. The connection of gene expression and drug metabolism by the GDH-synthesized RNA has not been demonstrated experimentally. The regulation of the mRNAs encoding the drug-metabolizing enzymes was studied by northern hybridization using the GDH-synthesized RNAs as probes. The mRNAs encoding cytochrome P-450 reductase, UDPglucosyltransferase, alternative oxidase, and ABC-transporters were upregulated by the administered ATP+UTP+GTP. Also superoxide dismutase and GSH S-transferase were upregulated by administered ATP. The untreated control, GTP, and UTP did not upregulate any of the mRNAs. The mRNAs encoding the enzymes were coordinately regulated at the molecular level. All the enzymes are also active in drug detoxication in mammals. Photometric assays of enzyme activities confirmed that the enzymes were present at levels proportional to their respective encoding mRNAs as detected by the GDH-synthesized RNA probes. Genetic code-based nucleic acid probes were partially accurate in detecting the mRNAs encoding the enzymes. Therefore, GDH-synthesized RNAs are important genetic metabolic probes for the screening of mRNAs encoding the drug metabolizing enzymes. Nucleoside triphosphates and analogs are antihypertensives, antineoplastics, antiarrhythmics, antimetabolites, antiviral agents etc and they induce GDH isomerization.
\end{abstract}

Keywords: Glutamate dehydrogenase-synthesized RNA, nucleotides, periodic sequence repeats, mRNA abundance, cytochrome P450, GSH S-transferase.

\section{INTRODUCTION}

Drugs and xenobiotic chemicals are metabolized by an array of enzymes [1,2,3]. Structure-activity relationships of drug metabolizing enzymes and their substrates are important research approaches in drug metabolism and transport [4]. It is important to incorporate metabolism research early in the pre-clinical drug screening process because poor pharmacokinetics account for a high proportion of clinical failures of drugs. Pre-clinical metabolic screening of a potential drug is also an expensive process because of public demand that the benefits and side effects be fully known prior to marketing of a drug. The novel fields of RNAi and transgenic animal modeling are fast-forwarding the pace of toxicological studies. These issues call for continued development of innovative methodologies in the pharmacokinetic pre-clinical screening of potential drugs.

Genetic code-based nucleic acid probes and primers have supported the remarkable breakthroughs made by hybridization and polymerase chain reaction (PCR) techniques in genetic and genomic research. Since genetic code-based probes and primers are not necessarily metabolic in origin, the results derived from molecular biology experimentation in which they are utilized in the analyses may or may not represent the physiological conditions studied. Furthermore, the pharmacokinetics of a potential drug is not yet predictable with much accuracy because the combination of enzymes under a specified state of ill-health that are upregulated to

*Address correspondence to this author at the CARC, Prairie View A\&M University, P.O. Box 519-2008, Prairie View, Texas 77446, USA;

E-mail: goosuji@pvamu.edu metabolize the drug is regularly changing. Therefore, there is need to develop specific genetic metabolic approach, different from the conventional genetic chemical approach for studying the responses of genes and diseases to administered drugs. Drug metabolism is generally treated in three phases [5]. Phase I enzymes modify the drug molecules by oxidation, dealkylation, and hydroxylation. Phase II enzymes conjugate the drugs to glutathione, sulfate, or carbohydrates. The phase III enzymes transport or clear-out the modified drugs. Metabolic transformations of structurally related drugs are influenced by many variables including enzyme isoforms, cell types, age, physiology, gender etc $[6,7,8]$. Although drugs are designed to target specific macromolecules, no universal genetic metabolic process that connects drug metabolism, disease and genes has been described. This has hampered the rapid development of new drugs using the wealth of bioinformatics knowledge now available [9]. The molecular relationships between adverse drug reactions [10] and many disease conditions that are exacerbated by genetic variations and single-nucleotide polymorphisms [11] have not been clearly understood. Therefore, it is important to understand the universal biological process that connects drug metabolism, disease conditions and genes. This calls for studies on drug metabolism at the molecular level in conjunction with pharmacokinetic studies. The templateindependent synthesis of RNA by glutamate dehydrogenase (GDH) $[12,13]$ in response to xenobiotic chemicals could be part of the universal biological process that links gene expression, drug metabolism and disease.

The isomerization of GDH is initiated by the fragmentation of some of its subunit polypeptides upon the binding of nucleophilic drugs to the active site lysine residue to form 
dead-end enzyme-substrate complexes [14]. The active site lysine residue is first activated for nucleophilic attack by Schiff base formation with $\alpha$-ketoglutarate. Nucleophiles with negative reduction potentials induced more fragmentation of GDH than nucleophiles with positive reduction potentials [15]. Thus, GDH isoenzyme population is a biomarker system for monitoring cellular redox changes. $\mathrm{Nu}-$ cleophilic substrates (nucleoside triphosphates) possessing both binding and polymerization groups were polymerized to RNA [16]. Therefore, the RNA synthetic activity of GDH was discovered in the course of the enzyme purification and kinetics experimentation $[15,17]$. The RNA synthetic activity is dependent on the enzyme's hexameric subunit structure because when the hexamer was dissociated in the absence of substrates, the aminating and deaminating oxidoreductase activities were retained, but the RNA synthetic activity was lost. These properties differentiated GDH from other enzymes including aldolase [18], acetoacetate decarboxylase [19], aminolevulinic acid dehydratase [20], DNA glycolase [21], and acetylserine sulfhydrylase [22] that depend on the formation of Schiff base reaction intermediate. Nucleophilemediated fragmentation of the GDH subunit polypeptides was followed by de novo biosynthesis of replacement polypeptides, thus giving rise to a new population of isoenzymes [17]. The primary structure of the RNAs synthesized by the enzyme is dependent on the subunit compositions and their arrangements in the hexameric isoenzymes [23]. Therefore, a new population of RNA was synthesized by the enzyme each time another drug was administered. Short sequences (3-30 nucleotides) of GDH-synthesized RNAs share homology with many mRNAs including those encoding NADH dehydrogenase (respiration), ribosomal proteins (translation), proteasome ATPase, UDP-glucosyltransferase, chitinase, acetyl-CoA carboxylase, lipoxygenase etc [12] thus indicating a possible role of the enzyme in the regulation of drug metabolism. Results from northern hybridization studies in which the GDH-synthesized RNAs were used as probes suggested their involvement in the reprogramming of the abundance of mRNAs, and in the coordinate regulation of catabolism and anabolism [18]. It is not yet possible to detect early signs of unfavorable drug metabolism by analysis of the target mRNAs [5] because cellular expression levels vary considerably from one gene to another [24] and the genetic code-based nucleic acid probes utilized in the hybridization are unable to discriminate and/or integrate hybridization signals with reference to mRNA concentrations. Hairpins, loops and other secondary structural conformations in the mRNAs are the major culprits because they tend to limit the optimal hybridization of probes/primers to target sites in the mRNA. Therefore novel metabolic and interdisciplinary approaches are needed in order to synthesize appropriate nucleic acid probes requisite for gaining deeper insights into the regulation of drug metabolism and similar complex biological processes.

The aim of this project was to develop genomic metabolic nucleic acid probes for monitoring the changes in the abundance of mRNAs encoding the drug-metabolizing enzymes in their responses to administered drugs. Nucleotides are structurally and metabolically related. Also, some of their analogues are HIV and viral DNA reverse transcriptase inhibitors [25] antihypertensives, antineoplastics, antiarrhythmics, antimetabolites etc and they induce GDH isomeriza- tion. Their pharmacokinetics and detoxication by the drugmetabolizing enzymes have not been studied extensively [26]. We report that in the metabolism of nucleoside triphosphates, the GDH-synthesized RNAs upregulated the mRNAs encoding NADPH-cytP-450 reductase (CPR), superoxide dismutase (SOD), and GSH S-transferase (GST) thus demonstrating the connection of genes, drug metabolism, and the environment.

\section{MATERIALS AND METHODS}

Treatment of experimental organism (Arachis hypogaea L. cv. Valencia seedlings) with the drugs, purification of GDH isoenzymes, synthesis of RNA by GDH, cDNA synthesis, differential display sequencing gel fractionation, structural and functional characterization of the RNAs sideby-side with total RNA, and cloning were as described before [12, 23].

\section{Northern Blot Analysis}

Total RNA was extracted from the control and treated seedlings using the acidic phenol/chloroform method [27] and were further cleaned-up with QIAGEN total RNA purification kit (QIAGEN, Valencia, CA, USA). Equal amounts $(10 \mu \mathrm{g})$ of total RNAs were loaded and electrophoresed on $2 \%(\mathrm{w} / \mathrm{v})$ agarose gels and photographed to verify quality and accurate normalization for quantity and equality of RNA loading. RNA was electro-transferred with Trans-Blot SD cell (Bio-Rad, Hercules, CA) from the electrophoresed gel onto Brightstar-Plus nylon membranes (Ambion, Foster City, CA, USA) and immobilized to the membrane by oven heating at $85{ }^{0} \mathrm{C}$ for $2 \mathrm{~h}$. Electro-transfer was continued to a second nylon membrane to verify completeness of the total RNA transfer.

For the preparation of probes from the GDH-synthesized RNAs, the cDNAs inserted in pCR4-TOPO vector were amplified by PCR from the plasmids (10 ng) using T7 forward and T3 reverse primers $(1 \mu \mathrm{M}$ each $),\left[\alpha^{32} \mathrm{P}\right] \mathrm{dATP}(3000$ $\mathrm{Ci} / \mathrm{mmol}, 10 \mathrm{mCi} / \mathrm{mL}, 2 \mu \mathrm{L}), \mathrm{dCTP} / \mathrm{dGTP} / \mathrm{TTP} \operatorname{mix}(50$ $\mathrm{mM}, 2 \mu \mathrm{L}), \mathrm{Taq}$ polymerase $(1 \mathrm{U})$, in a final volume of 30 $\mu \mathrm{L}$. Amplification was for 35 cycles $\left(95{ }^{0} \mathrm{C}\right.$ for 60 seconds, $55{ }^{0} \mathrm{C}$ for 30 seconds, and $72{ }^{\circ} \mathrm{C}$ for 60 seconds), followed by final extension incubation at $72{ }^{0} \mathrm{C}$ for $10 \mathrm{~min}$. Unincorporated nucleotides were removed from the labeled cDNA by Sephadex G50 chromatography.

The first and corresponding second nylon membranes with immobilized total RNA were prehybridized with ULTRAhyb buffer (Ambion, Foster City, CA, USA) at $68{ }^{\circ} \mathrm{C}$ for $30 \mathrm{~min}$, and hybridized with ${ }^{32} \mathrm{P}$-labeled cDNA as probes overnight at $68{ }^{\circ} \mathrm{C}$. The membranes were washed separately for $15 \mathrm{~min}$ at $42{ }^{0} \mathrm{C}$ to remove unbound probes, followed by another wash for $15 \mathrm{~min}$ at $68{ }^{\circ} \mathrm{C}$ to remove loosely bound probes, the wash solution being NorthernMax low stringency solution (Ambion, Foster City, CA, USA). The blots were exposed to $\mathrm{X}$-ray film with intensifying screens at $-80{ }^{0} \mathrm{C}$ for autoradiography. The band intensities were digitalized using UN-SCAN-IT gel digitizing software (Silk Scientific, Inc., Orem, Utah, USA). The digital intensities were normalized with the band of the control seedlings mRNA as the base line of 1 instead of zero [13]. For the upregulated mRNAs, the band intensities were rated on a scale of 1(normal band intensity) to 10 (highest band intensity) per blotted membrane. 
For the downregulated mRNAs, the band intensities were rated on a scale of -10 (lowest band intensity) to 1 (normal band intensity) per blotted membrane.

\section{Enzyme Extraction and Assays}

Freshly harvested seedlings (10g) were homogenized with $80 \mathrm{ml}$ of phosphate buffer $(50 \mathrm{mM}$ potassium phosphate containing $10 \%$ glycerol, $1 \mathrm{mM}$ dithiothreitol, and $0.1 \mathrm{mM}$ EDTA) $\mathrm{pH}$ 7.6. The homogenate was frozen at $-80{ }^{0} \mathrm{C}$, thawed at $4{ }^{0} \mathrm{C}$ in order to fracture the mitochondria. Cellular debris was removed by centrifugation $(20,000 \mathrm{x}$ g for $1 \mathrm{~h}$ at $2{ }^{0} \mathrm{C}$ ). The pellet was discarded, but the supernatant was dialyzed for $36 \mathrm{~h}$ against 5 changes of $50 \mathrm{mM}$ potassium phosphate buffer ( $\mathrm{pH} 7.6$ ) each change being $5 \mathrm{~L}$ to remove metabolites. The dialyzed extract was centrifuged $(5000 \mathrm{x} \mathrm{g}$ for $30 \mathrm{~min}$ at $4{ }^{\circ} \mathrm{C}$ ) to remove insoluble materials. The CPR and SOD activities of the extract were assayed with nitrotetrazolium bromide (MTT: 3-(4,5-dimethylthiazol-2-yl)-2,5diphenyltetrazolium bromide) as the substrate [28, 29]. Con-

Table 1. cDNAs of Some Total RNA Fragments and of the GDH-Synthesized RNAs Used as Probes for the mRNAs Encoding the Drug Metabolizing Enzymes

\begin{abstract}
Fragment 1 (synthesized by GDH):
TCGANATTACTGNNCGTAAGCGCACGCAGNGGNTTTGTTTAAGTCAGATGTGAAATCCCCNGGGCTCA ACCTGGGAACTGCATCTGA TACTGGCAAGCTTGAGTCTCGTAGAGGGGGGTAGAATTCCAGGTGTAGC GGTGAAATGCGTAGAGATCTGGAGGAATACCGGTGG CGAAGGCGGCCCCCTGGACCAACACTGACGC TCAGGTGCGAAAGCGTGGGGAGCAAACAGGATTAGATACCCTGGTAGTCCACGCCC TAAACGATGTC AACTTGGAGGTTGTGCCCTTGAGGCGTGGCTTCCGGAGCTAACGCGTTAAGTCGACCGCCTGGGGAGTACGGCCGCA AGGTTAAAACTCCAAGGAATTGACGGG

Fragment 2 (synthesized by GDH):

TTAACGCGTTAGCTTCGATACTGCGTGCCAAATTGCACCCAACATCCAGTTCGCATCGTTTAGGGCGTGGACTACCAGGGTATCTAATCC TGTTTGCTCCCCACGCTTTCGTGCCTCAGTGTCAGTGTTGGTCCAGGTAGCTGCCTTCGCCATGGATGTTCCTCCTGATCTCTACGCATTTCA CTGCTACACCAGGAATTCCGCTACCCTCTACCACACTCTAGTCGCCCAGTATCCACTGCAGTTCCCAGGTTGAGCCCAGGGCTTTCACAAC GGACTTAAACGACCACCTACGCACGCTTTACGCCCAGTAATTCCGAGTAACGCTTGCACCCTTCGTATTACCGCGGCTGCTGA

Fragment 3a (synthesized by GDH):

TCGANATTACTGGGCGTAAGCGTGCGTCTAGNTGGNTCNTNTTTAAGTCCGATTGTGAAAATGCCCTGGGCTCNACCTGGGAACTGCATC TGGATACTGGGCGACTAGAGTGTGGTAGAGGGTAGCGGAATTCCTGGTGTAGCAGTGAAATGCGTAGAGATCAGGAGGAACATCCATG GCGAAGGCAGCTACCTGGACCAACACTGACACTGAGGCACGAAAGCGTGGGGAGCAAACAGGATTAGATACCCTGGTAGTCCACGCCC TAAACGATGCGAACTGGATGTTGGGTGCCATTTGGCACGCATTATCGAAGCTAACGCGTTAAGTTCGCCGCCTGGGGAGTACGGTCGCA AGACTGAAACTCAAAGGAATTGACGGNNA
\end{abstract}

Fragment 3b (from total RNA, homologous to fragment \#3a):

TCGNNNATTACTGGGNNNAAGCGCAGCGCNAGGCGGTTNTTGNTTAAGTCACGATGTGAAATCCCCTGGGCTCAACCTGGGAACTGCAT CTGATACTGGCAAGCTTGAGTCTCGTAGAGGGGGGTAGAATTCCAGGTGTAGCGGTGAAATGCGTAGAGATCTGGAGGAATACCGGTGG CGAAGGCGGCCCCCTGGACGAAGACTGACGCTCAGGTGCGAAAGCGTGGGGAGCAAACAGGATTAGATACCCTGGTAGTCCACGCCG TAAACGATGTCGACTTGGAGGTTGTGCCCTTGAGGCGTGGCTTCCGGAGCTAACGCGTTAAGTCGACCGCCTGGGGAGTACGGCCGC AAGGTTAAAACTCAAAGGAATTGACGG

Fragment 4 (synthesized by GDH):

GCTGGTAAGGNTGGNCTTTAAGTCCGTTGTGAAAGCCTGGGCNCCNTCTAGANGANCTGCAGTGGAACTGGGCGACTANAGTGTGCCCA TANGGTCCCGGAATTCCTGGTGTAGCAGTGAAATGCGTATAGATCAGGAGGAACNTCCATGGCGAAGGCAGCTACCTGGANCANCACTG ACACTGAGGCACGAAAGCGTGGGGAGCCAACAGGATTAGATACCCTGGTAGTCCCCGCTCTAAACGATGCNAATT

Fragment 5a (synthesized by GDH):

GGGGCTTAACGATTCGCCCTTATGAGTCCTGACCGAGAACGGCATTGATAGCGATGAGTCCTGACCGACAACGGCATTGATAGCGAT GAGTCCTGACCGAGAACGGCATTGATAGCGATGAGTCCTGACCGACAACGGCATTGATAGCGATGAGTCCTGACCGAGAACGGCAT TGATAGCGATGAGTCCTGACCGAGAACGGCATTGATAGCGATGAGTCCTGACCGACAACGGCATTGATAGCGATGAGTCCTGAC CGACAACGGCATTGATAGCTATGAGTCCTGACCGAGAACGGCATTGATAGCGATGAGTCCTGACCGACAACGGCATTGATAGCGA TGAGTCCTGACCGACAACGGCATTGATAGCGATGAGTCCTGACCGACAACGGCATTGATAGCATGAGTCCTGACCGACAACGGCA TTGATAGCGATGAGTCCTGACCGGGTACGCAGTCTACGAGACCAGT

Fragment 5b (from total RNA, homologous to probe \#5a):

ACTTCAGCTACGATTCGCCCTTATGAGTCCTGACCGAGAACGGCATTGATAGCGATGAGTCCTGACCGACAACGGCATTGATAGCGA TGAGTCCTGACCGACAACGGCATTGATAGCGATGAGTCCTGACCGAGAACGGCATTGATAGCGATGAGTCCTGACCGATGGTTCA CGGGATTCTGCAATTCACACCAAGTATCGCATTTCGCTACGTTCTTCATCGGGTACGCAGTCTACGAGACCAGTAA

Fragment 6 (synthesized by GDH):

ACAGCAGCTACGATTCGCCCTTTGAGTCCTGACCGAGAATGGCATTGATAGCGATGAGTCCTGACCGACAACGGCATTGATAGCGA TGAGTCCTGACCGACAACGGCATTGATAGCGATGAGTCCTGACCGACAACGGCATTGATAGCGATGAGTCCTGCCCGGGTACGCAGTC TACGAGACCAGTA

Fragment 7 (rRNA from total RNA):

CGAGAACTGGCGATGCGGGATGAACCGGAAGTCGGGTTACGGTGCCCAACTACGCGCTAACCTAGACCCCACAAAGGGTGTTGGTCGACT TCCATGACCACCGTCCTGCTGTCTTAATCGACTTCCATGACCACCGTCCTGCTGTCTTAATCGACTTCCATGACCACCGCCCTGCTATCT TAATCG 
tinuous photometric measurements at $\mathrm{A}_{610}$ with MTT were carried out using $0.9 \mathrm{ml}$ of mixture as follows: $13 \mu \mathrm{mol} \mathrm{MTT}$ in $0.1 \mathrm{M}$ potassium phosphate buffer $(\mathrm{pH} 7.6)$ and $0.25 \mathrm{ml}$ of enzyme extract containing $1.0-5.0 \mathrm{mg}$ protein $\mathrm{ml}^{-1}$. Readings were taken (NanoDrop ND-1000 spectrophotometer) every other min for $10 \mathrm{~min}$. Then $0.1 \mathrm{ml}$ of $0.5 \mathrm{mM} \mathrm{NADPH}$ solution in $0.1 \mathrm{M}$ potassium phosphate buffer ( $\mathrm{pH}$ 7.6) was added, and photometric readings were recorded for another $10 \mathrm{~min}$. An extinction coefficient of $11.3 \mathrm{mM}^{-1} \mathrm{~cm}^{-1}$ was used to calculate the number of moles of MTT converted to the blue-formazan $\mathrm{min}^{-1} \mathrm{mg}^{-1}$ protein [30] in the absence of NADPH (SOD activity) and in the presence of NADPH (CPR activity). Blank assays without MTT but with enzyme extract, and with MTT but without enzyme extract were also performed. Positive controls in the CPR and SOD assays with added $30 \mathrm{nmol}$ NADPH-CPR (Invitrogen, Carlsbad, CA, USA) per assay were performed. Assays were repeated four times on two extracts of enzymes from each treated seedlings, and the means were calculated.

\section{RESULTS}

\section{GDH-Synthesized RNAs}

The GDH-synthesized RNA fragments that shared sequence homology with the mRNAs encoding some of the drug metabolizing enzymes had sequence repeats (Table 1) because their primary structures are dependent on the subunit compositions of the hexameric isoenzymes [23]. GDH has a non-allelic gene structure [31] consisting of three different subunit polypeptides. The gene $\left(\mathrm{GDH}_{1}\right)$ encoding the more acidic subunits $(\mathrm{A}$, and $\alpha$ ) is heterozygous, and co-dominant; and the gene $\left(\mathrm{GDH}_{2}\right)$ encoding the less acidic subunit $(\beta)$ is homozygous [32]. The binomial distribution pattern of the $28 \mathrm{GDH}$ hexameric isoenzymes [33] is a protein population array that displays the subunit relationships. Accordingly, the primary structures of RNAs (Table 1) synthesized by the charge isomers mimicked the subunit compositions and relationships among the isoenzymes. The NCBI BLAST 2 sequences alignment algorithm [34] showed that isoenzymes with similar subunit compositions $\left(\mathrm{A}_{3} \alpha_{3}, \alpha_{3} \beta_{3}, \mathrm{~A}_{3} \beta_{3}\right.$ etc) synthesized RNAs (fragments $1,3 \mathrm{a}$, and 4 ) that shared extensive plus/plus strands sequence similarities. Isoenzymes with calibrated similarities in their subunit compositions $\left(\mathrm{A}_{4} \alpha \beta\right.$, $\mathrm{A}_{3} \alpha \beta_{2}, \mathrm{~A}_{2} \alpha_{2} \beta_{2}, \mathrm{~A}_{2} \alpha \beta_{3}$ etc) synthesized RNAs (fragments 5a and 6 ) that shared repeated overlapping plus/plus strands sequence similarities. Isoenzymes with opposite subunit compositions $\left(\alpha_{5} \beta, \alpha \beta_{5}, \mathrm{~A}_{5} \beta\right.$ etc) synthesized RNAs (RNA fragments 1, 2, and 3a) that shared plus/minus strands sequence similarities. Therefore GDH-synthesized RNAs, similar to their corresponding isoenzymes are isomeric RNAs. Their isomeric sequence characteristics distinguished them from transcribed RNA. The relationship between GDH subunit composition and the RNA synthesized suggested that each subunit polypeptide possessed positional specificity and orientation in the hexameric isoenzyme. Their positional specificity is in agreement with the massive change in the structure and loss of catalytic activity consequent upon the dissociation of the hexamer [35]. The network of repeated overlapping sequence similarities among the GDHsynthesized RNA thus offered a basis for verifying the fidelity of the enzyme in the synthesis of RNA. The sequence similarities were also instrumental to the ability of the RNA to coordinately reprogram the abundance of mRNAs [23] in agreement with the signal integration and discrimination property of GDH $[15,17]$. The sequence overlaps conferred strong specificity on the GDH-synthesized RNA as probes for detecting mRNAs.

\section{Application of GDH-Synthesized RNA in Drug Metabo- lism}

The BLAST searches as done before [12, 23] showed that the listed GDH-synthesized RNAs matched knownfunction genes (Table 2) encoding the phases I, II, and III drug-metabolizing enzymes. A comparison of the sequences (Table 1) with their putative functions (Table 2) showed that the drug-related GDH-synthesized RNAs were derivatives, permutations, inversions, transpositions, repeats or rearrangements involving RNA fragment \#1 or \# 5a. The two common frames of sequences were in agreement with the isomeric nature of the GDH-synthesized RNAs.

Northern blotting was preferred to microarray and/or PCR techniques because the GDH-synthesized RNAs were multi-target probes that required the fractionation of the mRNAs prior to probing [23]. Northern analysis performed to verify the interaction of GDH-synthesized RNA with the several putative targets in mRNAs displayed multiple bands (Figs. 1-5). In each northern blot, the band patterns and intensities of the control peanut total RNA were taken as the baseline [36]. The Northern bands were distinct and compact without any smearing, thus confirming that the total RNA preparations were free from ribonuclease degradation. Furthermore, the rRNA bands were present as evidenced in the photographed gels thus confirming that total RNA preparations used were free of any degradation. The duplicate northern analyses using each cDNA of GDH-synthesized RNA gave identical banding patterns thus confirming reproducibility of the northern reactions. The second nylon membrane onto which the total RNAs were trans-blotted gave no bands after hybridization to labeled probes thus confirming completeness of total RNA transfer to the first membrane. mRNAs encoding some housekeeping enzymes were not applied as controls because northern results in which GDHsynthesized RNA were used as probes tended to suggest that such mRNAs were also subject to environmental reprogramming of their abundance (unpublished results). Therefore the important reference control was the total RNA of the untreated control seedlings since their GDH isoenzyme population pattern was superseded by those of the treated seedlings [37]. The abundance (Table 3) of the mRNAs detected by the Northern analysis (Figs. 1-5) showed dramatic reprogramming in response to each drug. Changes in redox potentials induced by the drugs (nucleoside triphosphates) determined the extent of GDH isomerization and of the RNAs the isoenzymes synthesized [36,37].

Probe \#1 shared sequence homologies with two mRNAs: $\sim$ 1,800 bases long encoding CPR, and 6,000 bases long encoding indole acetic acid (IAA) inducible protein. The mRNA encoding CPR was most upregulated (10-fold) by the application of 3NTPs. The single nucleotide treatments (ATP, CTP, GTP, UTP), and the control did not induce the mRNA thus emphasizing the similarities in the nucleotide structures and suggesting that they were slowly metabolized. $\mathrm{CPR}$ is rated as the most ubiquitous mechanism for drug detoxication $[38,39]$ because it can perform a wide spectrum 
Table 2. cDNA of RNA Fragments and their Putative Functions

\begin{tabular}{|l|l|l|}
\hline RNA Fragment & Putative Function & Accession \# \\
\hline \hline 1. & $\begin{array}{l}\text { Indole acetic acid inducible genes } \\
\text { Cytochrome P450 reductase }\end{array}$ & $\begin{array}{l}\text { X68218.1 } \\
\text { AF123602.1 }\end{array}$ \\
\hline 2. & $\begin{array}{l}\text { Transcriptional factor } \\
\text { Superoxide dismutase }\end{array}$ & AB182945.1 \\
& AY642137.1 \\
\hline $3 a$. & Aranslational factor & AJ132231.1 \\
\hline 4 & Translational factor & EF187463.1 \\
\hline $5 a$. & GSH S-transferase & AJ13223.1 \\
\hline 6. & ABC transporters & AF243366.1 \\
\hline Acid lipase & BK001008.1 & AY360221.1 \\
\hline 7. & $\begin{array}{l}\text { Aroton pump } \\
\text { ATPase }\end{array}$ & Y09815.1 \\
\hline
\end{tabular}

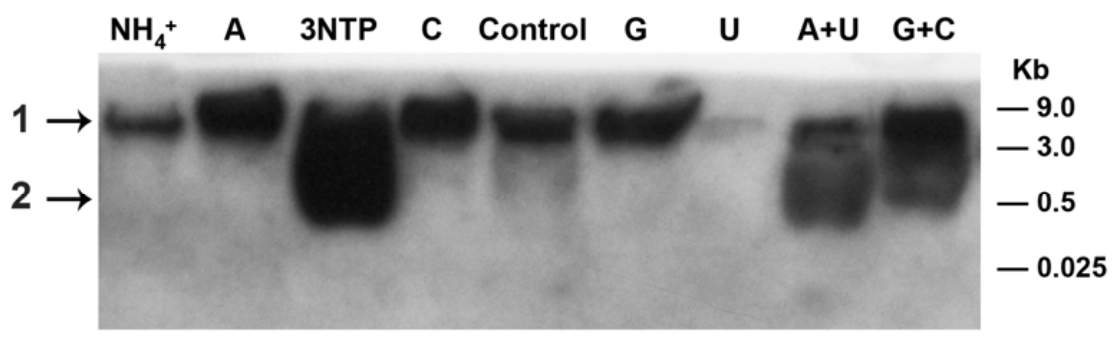

Fig. (1). Northern blot with fragment 1 (IAA inducible protein and cytP-450) as probe: Equal amounts (10 $\mu \mathrm{g})$ of total RNAs from the control, and from $\mathrm{NH}_{4} \mathrm{Cl}$, ATP, 3NTPs, CTP, GTP, UTP, ATP+UTP, GTP+CTP-treated peanuts were electrophoresed through $2 \%$ agarose gel, transblotted on to nylon membrane, followed by screening with ${ }^{32} \mathrm{P}$-labelled cDNA of the probe. The membrane was washed with low stringency solution and autoradiographed. Band $\{1\}$ is the mRNA encoding auxin inducible protein; and band $\{2\}$ is the mRNA encoding cytP-450.

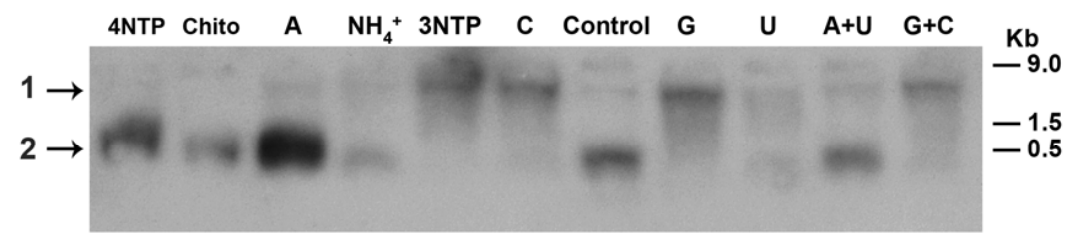

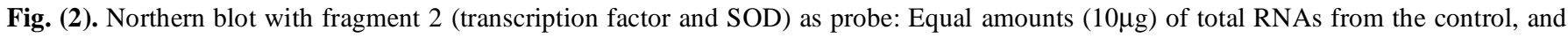
from 4NTPs, Chitosan, ATP, $\mathrm{NH}_{4} \mathrm{Cl}$, 3NTPs, CTP, GTP, UTP, ATP+UTP, GTP+CTP-treated peanuts were electrophoresed through $2 \%$ agarose gel, trans-blotted on to nylon membrane, followed by screening with ${ }^{32} \mathrm{P}$-labelled cDNA of the probe. The membrane was washed with low stringency solution and autoradiographed. Band $\{1\}$ is the mRNA encoding transcription factor; band $\{2\}$ is the mRNA encoding SOD.

of reactions including $\mathrm{N}$-oxidation, sulfoxidation, epoxidation, N-, S-, and O-dealkylation, peroxidation, deamination, desulfuration, and dehalogenation [40]. Plants possess functionally active CPR [41]. Pharmacokinetic screening of potential drugs is focused mainly on the inducible mammalian CPR [42, 43]. Therefore, the results presented hereunder are relevant in plants as they are in animals. Nucleotides are signaling molecules [7] and the sources of biological energy [8]. Also, some of their analogs are antiviral agents, antihypertensives, antineoplastics, antiarrhythmics, antimetabolites etc. Therefore, suppression of the mRNA encoding CPR by GDH-synthesized RNA in plants could be an important model for the identification of potential drug candidates. Administered as mixes (ATP plus UTP, GTP plus CTP, 

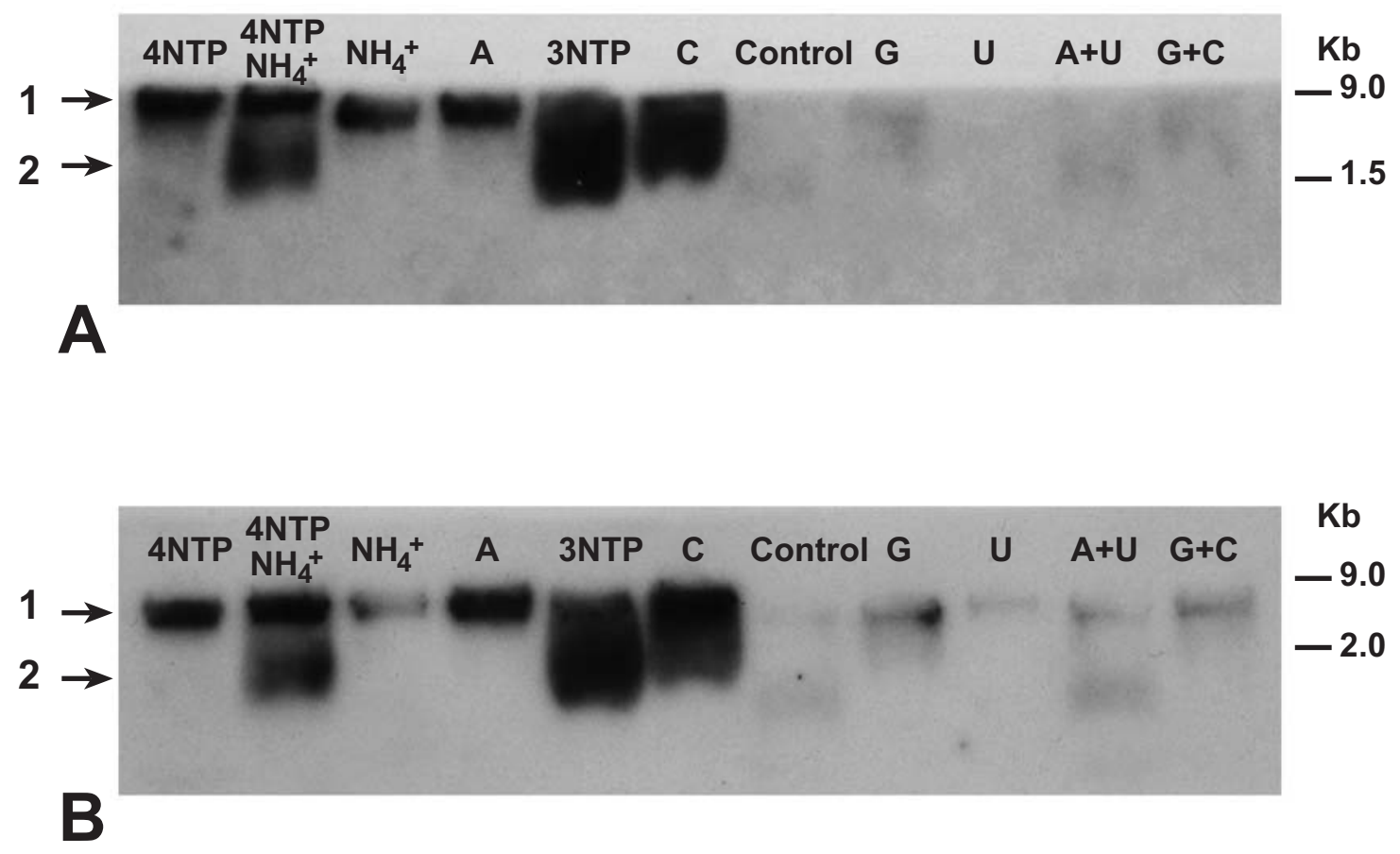

Fig. (3). Northern blots with fragments $3 a$ (from GDH-synthesized RNA) and fragment 3b (from total RNA) homologous to mRNAs for translation factor and $\mathrm{AOX}$ as probes: Equal amounts $(10 \mu \mathrm{g})$ of total RNAs from the control, and from $4 \mathrm{NTPs}, 4 \mathrm{NTPs}+\mathrm{NH}_{4} \mathrm{Cl}, \mathrm{NH}_{4} \mathrm{Cl}, \mathrm{ATP}$, 3NTPs, CTP, GTP, UTP, ATP+UTP, GTP+CTP-treated peanuts were electrophoresed through $2 \%$ agarose gel, trans-blotted on to nylon membrane, followed by screening with ${ }^{32} \mathrm{P}$-labelled cDNA of the probe. The membrane was washed with low stringency solution and autoradiographed. Band $\{1\}$ is the mRNA encoding ribosomal protein; band $\{2\}$ is the mRNA encoding AOX.

4NTPs, $\mathrm{NH}_{4}{ }^{+}$plus 4 NTPs), the drugs elicited CPR-mediated detoxication responses (Fig. 1) thus emphasizing the metabolic importance of the synergistic structural complementarity between the purine and pyrimidine nucleotides. CPR is considered as a housekeeping enzyme because of its low level in many mammalian tissues. The gene encoding the enzyme also lacks 'TATA' and 'CCAAT' boxes in the promoter sequence similar to several genes encoding housekeeping enzymes [44] whose expressions are not readily modulated by inducers [45]. However, the abundance of its mRNA was readily modulated by NTPs (Fig. 1) thus demonstrating the limits of its suitability as a stable control transcript in differential gene expression studies [41]. The $\sim 6,000$ bases mRNA (Fig. 1) encoding the IAA-inducible protein was not further analyzed because its abundance did not affect the abundance of the mRNA encoding CPR. IAAinducible protein regulates plant growth [46]. Except the control and the UTP treatment, all the other treatments promoted the growth of the seedlings. The cellulose contents were also lowest in the control and the UTP-treated seedlings [47] in agreement with the relative abundance of the mRNA encoding the auxin-inducible protein (Fig. 1). The level of CPR protein was assayed in terms of NADPHmediated reduction of MTT. The mixes of NTPs induced higher activities of the enzyme as compared with the control and single NTP treatments (Table 4). Therefore the enzyme kinetics results agreed with the Northern blot results.

Probe \#2 shared homology with the mRNAs $\sim 770$, and 9,000 bases long encoding copper/zinc superoxide dismutase isoenzyme 2 (SOD2), and homeobox transcriptional protein respectively. Copper/Zinc SOD is a ubiquitous enzyme in the cytosol and chloroplast, and it catalyzes the dismutation of the superoxide anion into hydrogen peroxide and molecular oxygen [48]. It is one of the most important antioxidative enzymes. The mRNA encoding SOD2 was most upregulated by ATP as compared with the control, 4NTPs, and the combined ATP plus UTP administrations that displayed normal induction of the mRNA. The different response of the mRNA encoding SOD2 to the administered ATP could have been due to the suppression of the mRNA encoding CPR. The downregulation of the mRNA encoding SOD2 in the GTP plus CTP, 3NTPs, GTP, UTP, and CTP treated peanuts relative to the untreated control signified the prevalence of adverse pharmacokinetic conditions for the enzyme. Generally, there were reciprocal relationships between the levels of the mRNAs encoding CPR and SOD2 (Table 3). This was due to the plus/minus strands sequence similarity between probes 1 and 2. The regulation of the abundance of the two mRNAs was therefore attributable to the GDH-synthesized RNA.

The level of SOD protein was assayed in terms of the oxidation of MTT (Table 4) by superoxide anion [29]. The results showed that only ATP-treated peanut had the highest activity of the enzyme. Therefore the mRNA encoding SOD2 was correctly identified in the northern blot using the GDH-synthesized RNA fragment \#2 as the probe (Table 3 ). The confirmation of the abundance of mRNAs (Table 3) by the activities of the enzymes (Table 4) bring about a strong appreciation of the metabolic consequences of the GDHsynthesized RNAs as proposed earlier [23, 47] because the enzyme encoded by a mRNA suffered a loss-of-activity following the degradation of the mRNA by the homologous RNA that was synthesized by GDH. When the GDH did not synthesize the RNA, then the mRNA was not degraded, and 
there was no loss-of-activity by the enzyme. The advantage of GDH was that whereas the photometric assays of CPR and SOD2 could not detect the coordinate regulation of the enzymes, the GDH-synthesized RNA easily offered the molecular basis of the coordinate regulation, an important reaction in drug metabolism research. Therefore, it was very incisive to conduct pharmacokinetic experimentation in conjunction with molecular biology research.

Superoxide free-radicals [49] are produced in tissues as an adverse response of metabolism to drugs. $\mathrm{Cu} / \mathrm{Zn} \mathrm{SOD}$ of plants are similar to bovine erythrocyte $\mathrm{Cu} / \mathrm{Zn}$ SOD in possessing high catalytic efficiency and 2 atoms of $\mathrm{Cu}$ and $\mathrm{Zn}$ per molecule [50]. This structure is consistent with the mechanism of action of disproportionation which implies the alternative reduction and reoxidation of the enzyme metal $\left(\mathrm{Cu}^{2+}\right)$ during successive interaction with $\mathrm{O}_{2}^{-}$radicals [51]. Mutations in the $\mathrm{Cu} / \mathrm{Zn}$ SOD gene account for approximately $25 \%$ of familial amyotrophic sclerosis (ALS). Up to 105 different mutations have been identified in the SOD gene. Studies on the abundance of the mRNA encoding the SOD using GDH-synthesized probes could further illuminate the targets of the small molecules that induce the mutations [52]. Therefore, plant SOD results could be applied as a model to understand potential drug targets in mammalian systems; especially the upregulation of the mRNA encoding SOD2 by GDH-synthesized RNA could be important in ALS drug screening. Mammalian GDH also synthesizes RNA (unpublished result), but they have not been sequenced. The homeobox transcript was upregulated in the drug treatments where SOD2 was downregulated thus confirming [46] that adverse pharmacokinetics and oxidative stress caused the over-expression of transcriptional activity.

Probe \#3a (Table 1) shared homology with the mRNAs $\sim 6,500$, and 2,700 bases long encoding ribosomal proteins (translational factor), and alternative oxidase 2a (AOX2a) respectively. The mRNA encoding AOX2a was upregulated in the CTP and 3NTPs treatments but it maintained normal abundance in the control and the other NTP treatments (Fig. 3a) thus suggesting that the AOX2a activity complemented the activities of CPR and SOD2. This complementary action was attributable to the extensive plus/minus strand sequence similarity (Table 1) between probes 1, 2 and 3a, and emphasizing the usefulness of the GDH-synthesized RNA in drug metabolism research. As a negative control, fragment \#3b (Table 1) isolated from total RNA lane in the differential display sequencing gel, and sharing low (83\%) sequence similarity with probe \#3a was used as a northern probe (Fig. 3b). The northern band patterns for the mRNA encoding AOX2a (Fig. 3a and 3b) were similar qualitatively but remarkably different quantitatively because the total RNAderived probe detected only about $20 \%$ of the mRNA encoding AOX2a in the CTP-treated seedlings. This and other inadequacies also observed in the detection of the abundance of the mRNA encoding the ribosomal protein emphasized the limitation of genetic code-based nucleic acid probe in hybridization assays of mRNA [53]. The results of the Blast 2 sequences alignment between fragments $3 \mathrm{a}$ and $3 \mathrm{~b}$ displayed 4 gaps and 51 mismatches which introduced the flexibility that enabled the GDH-synthesized RNA to interact fully with its target mRNA to give maximum hybridization signals despite the impediment created by mRNA secondary structures. Because the genetic code-based probe $3 \mathrm{~b}$ matched the target mRNA perfectly, it was rigidly unable to flip around mRNA secondary structures with the consequence that its hybridization signals were lower than expected and substantially inaccurate [24]. The mRNA encoding the translational factor was regulated independent of that encoding the AOX2a in the 4NTPs and ATP treatments, but they were at normal abundance in the control, GTP, combined ATP plus UTP, combined GTP plus CTP, and UTP treatments thus further suggesting that these treatments elicited unfavorable pharmacokinetics that induced catalytic RNA synthesis by GDH. The results presented above could apply as a model for mammals because AOX-dependent cyanide-resistant 1 electron transport operates in mammalian mitochondria [54] where the enzyme remains inactive until triggered by pyruvate [55].

Probe \#4 (Table 1) shared homology with mRNAs $\sim 850$ and 6,500 bases long encoding glutathione S-transferase (GST) type II (phase II enzyme), and translational factor respectively (Fig. 4). The mRNAs encoding the GST and SOD were upregulated in the 4NTPs and ATP treatments in which AOX2a was downregulated, but were downregulated in 3NTPs and CTP treatments in which the mRNAs encoding AOX2a was upregulated (Table 3). Similar reciprocal relationships in the abundance of the mRNAs encoding the GST and CPR were also found. Therefore, like the mRNA encoding AOX2, that encoding GST responded positively to ATP administration. These results showed that the abundance of the mRNAs encoding the phase I enzymes was coordinately regulated by GDH-synthesized RNA. Furthermore, the abundance of the mRNA encoding GST (phase II) was coordinately linked to the abundance of the mRNAs encoding the enzymes of phase I by GDH-synthesized RNA. The GDH-synthesized RNA that was homologous to the mRNA encoding UDP-glucosyltransferase [47] shared sequence similarities with the GDH-synthesized RNAs that were homologous to the mRNAs encoding CPR, SOD, AOX2a, and GST (Table 1). The abundance of the mRNAs encoding UDP-glucosyltransferase (phase II) was reciprocally reprogrammed with respect to the mRNA encoding GST consequent upon 4NTPs, ATP, 3NTPs, GTP plus CTP, GTP, and CTP administrations [47]. Plant GSTs show a high degree of structural homology to animal GSTs [56]. They function to protect the cell from oxidative damage by quenching reactive molecules (pesticides, drugs, and carcinogens) with the conjugation of GSH [57]. However, they are known to possess broad substrate specificities [58]. As is common in GDH, there are also tissue location differences in GST. The GST purified from rat liver microsome was stimulated eightfold by the treatment with $\mathrm{N}$-ethylmaleimide and fourfold with iodoacetamide; whereas the soluble enzyme of rat liver cytoplasm was not affected by such sulfhydrylblocking agents [59]. The phase II enzymes were coordinately regulated at the molecular level by GDH-synthesized RNA. Assays of GSTs are major experimental activities in the pharmacokinetic screening of potential dermatological drugs [60]. Therefore, the results derived from plant GST could be applied as a model for drug screening in mammalian studies. These reprogramming of mRNA abundance suggested that GDH catalyzed the biological processes that connected gene expression, drug metabolism, and the environmental conditions. 
Probe \#5a (Table 1) shared homology with the mRNAs $\sim 6,300$ and 1,600 bases long encoding ATP-binding cassette (ABC) transporters and acid lipase respectively (Fig. 5a). ABC superfamily of transporters (phase III) participate in the excretion of xenobiotics and antifungal agents [61]. NTPs and analogs are substrates of various transporters [25]. The mRNA encoding the transporters was consistently upregulated by most of the nucleotide treatments compared with the control, thus confirming the excellence of the NTPs as transporter substrates for efficient salvage and detoxification [37]. The nucleotide treatments (4NTPs, GTP plus CTP, 3NTPs, ATP, and CTP) that upregulated the abundance of the mRNAs encoding the phases I and II enzymes also upregulated the abundance of the mRNAs encoding ABC transporters (Table 3). As a negative control, fragment \#5b (Table 1) isolated from total RNA lane in the differential display sequencing gel, and sharing very high $(>97 \%)$ sequence similarity with probe \#5a was used as a northern probe (Fig. 5b). Fig. (5) again illustrated the superiority of genetic metabolic nucleic acid probes over genetic code-based nucleic acid probes in hybridization screening because fragment $5 \mathrm{~b}$ shared 11 times plus/plus strands overlapping repeats with fragment $5 \mathrm{a}$. The northern band patterns for the mRNAs encoding $\mathrm{ABC}$ transporters and acid lipase in the two Figures were remarkably different, with probe $\# 5$ b being unable to detect any of the target mRNAs in the 3NTP and GTPtreated seedlings. There were also reciprocal differences in the abilities of the two probes to detect the two target mRNAs in the 4NTP, ATP, $\mathrm{NH}_{4}{ }^{+}, \mathrm{CTP}, \mathrm{ATP}+\mathrm{UTP}$, GTP+CTP-treated and the control seedlings suggestive of the limited ability of probe $\# 5 \mathrm{~b}$ to hybridize to the target mRNAs due most probably to mRNA secondary structures. Figs. (5a and 5b) demonstrated that despite the fact that the two probes hybridized to the same section of the target mRNA, the GDH-synthesized RNA was exceedingly more efficient than the genetic code-based probe in the detection of the mRNA abundance. This was due to probe \#5a being an eleven times overlapping repeat, it had higher probability to hybridize to the target mRNA by overcoming mRNA secondary structures. Hairpins, loops and other intramolecular base pairing in mRNA are some of the major factors that minimize the stability of duplexes in northern hybridization [24]. The eleven overlapping repeats permitted fragment \#5a to flip around secondary structures in the mRNA and to achieve optimal hybridization signal/sensitivity as compared with fragment \#5b. Therefore, the GDH-synthesized RNA (metabolism-based probe) was more able than the total RNA fragment (genetic code-based probe) to integrate and discriminate the signals for the regulation on mRNA abundance. The mRNAs encoding the ABC transporters and acid lipase were absent from the UTP-treated seedlings (Fig. 5). Uracil is the most oxidized pyrimidine base. Therefore, UTP treatment could have induced GDH to synthesize RNA fragment 5a which then degraded the mRNAs encoding the ABC transporters and acid lipase. Short fragments of RNA about 25 nucleotides in length, diagnostic of mRNA silencing phenomenon, have been detected in the total RNA of peanut seedlings whose GDH was actively synthesizing RNA [23].

Many drugs are hydrophobic and can pass through cell membranes. Hydrophobic drugs are susceptible to active efflux so that they maintain lower concentrations in the cells. All eukaryotic genomes encode several gene families capable of encoding multi-drug resistance functions, among which the $\mathrm{ABC}$ transporters are the largest. There are 49 human [62], 30 yeast, and 57 fly $\mathrm{ABC}$ transporter sequences in GenBank. ABC transporter is a single protein that specifically recognizes several structurally distinct classes of compounds and catalyzes their efflux from the cell. It is a highly conserved gene family [63]. ABC transporter assays are major experimental activities in pharmacokinetic screening of multidrug and breast cancer resistance drugs $[64,65]$. Therefore, the regulation of the mRNA encoding the plant ABC transporter reported above could be relevant to drug metabolism research in human tissues. The mRNA encoding the acid lipase was not studied further because it did not correlate with changes in the fat contents of the seedlings [66]. Lipase is an indicator of renal and pancreatic dysfunction. The inability of fragment $5 \mathrm{~b}$ to detect the mRNA encoding the enzyme in the $3 \mathrm{NTP}$, and GTP treatments further illustrated the limitations of genetic code-based nucleic acid probes in diagnostic clinical screening of disease conditions. Therefore generally, the GDH-synthesized RNAs regulate metabolism. They could most practically be useful in the pre-clinical molecular and pharmacokinetic screening of the drug metabolizing enzymes because the results spill over to facilitate the clinical research proper.

Probe \#6 shared homology with three mRNAs. The high molecular weight mRNA ( 12,500 bases long) encoding p2-t protein (flavonoid biosynthesis), the 4,500 bases long mRNA encoding pleiotropic drug resistance 9 protein (ATPase) coupled to transmembrane movement of substances, and the 800 bases long mRNA encoding the transmembrane

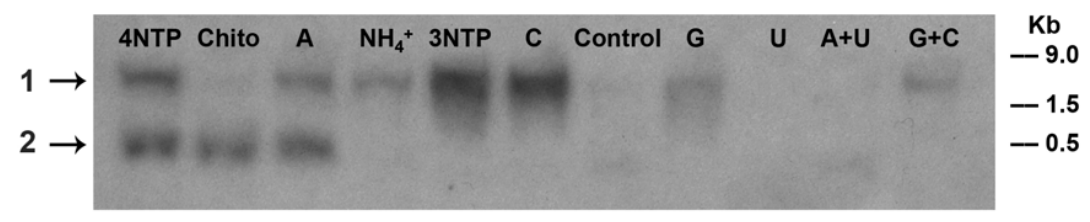

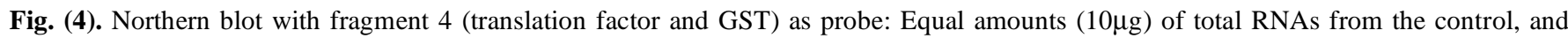
from 4NTPs, Chitosan, ATP, $\mathrm{NH}_{4} \mathrm{Cl}$, 3NTPs, CTP, GTP, UTP, ATP+UTP, GTP+CTP-treated peanuts were electrophoresed through $2 \%$ agarose gel, trans-blotted on to nylon membrane, followed by screening with ${ }^{32} \mathrm{P}$-labelled cDNA of the probe. The membrane was washed with low stringency solution and autoradiographed. Band $\{1\}$ is the mRNA encoding ribosomal protein, band $\{2\}$ is the mRNA encoding GST. 

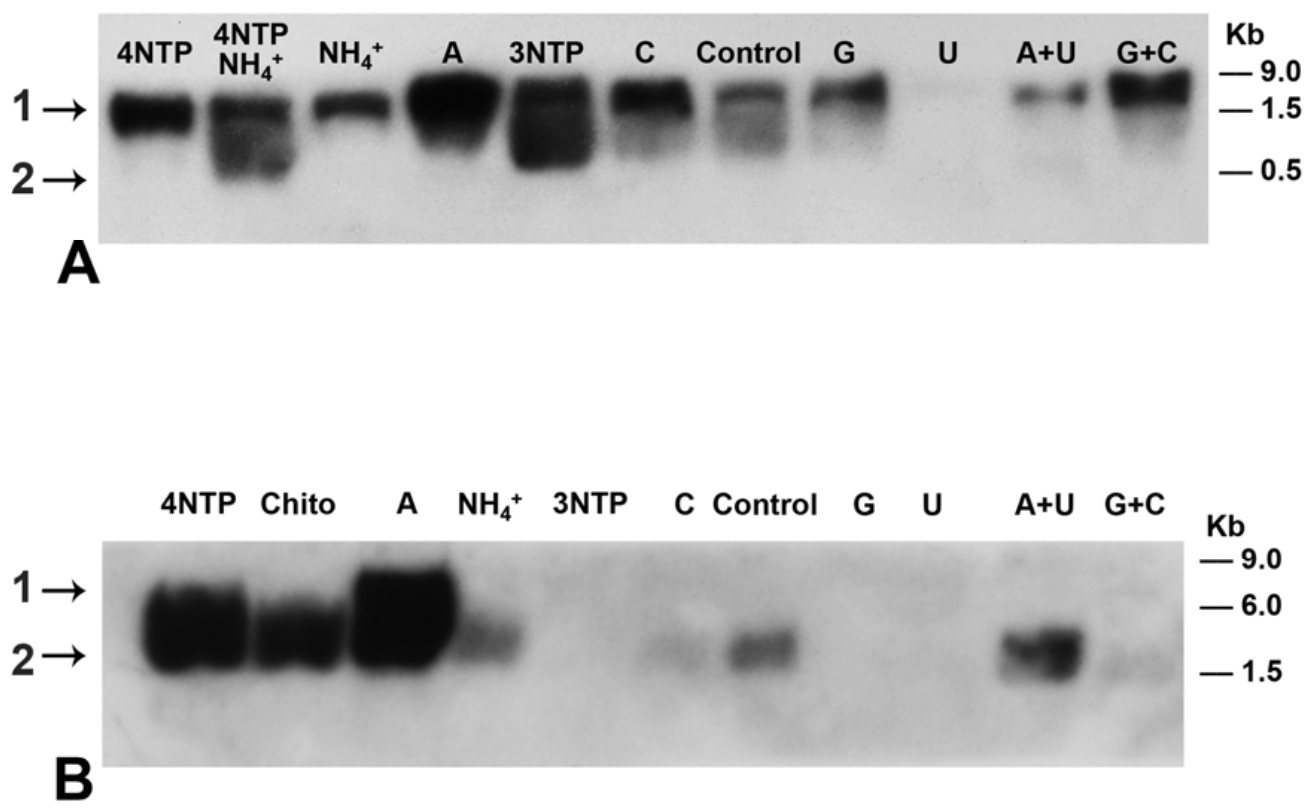

Fig. (5). Northern blots with fragment 5a (from GDH-synthesized RNA) and fragment 5b (from total RNA) homologous to mRNAs for ABC transporter and acid lipase as probes: Equal amounts $(10 \mu \mathrm{g})$ of total RNAs from the control, and from $4 \mathrm{NTPs}, 4 \mathrm{NTPs}+\mathrm{NH}_{4} \mathrm{Cl}, \mathrm{NH}_{4} \mathrm{Cl}, \mathrm{ATP}$, 3 NTPs, CTP, GTP, UTP, ATP+UTP, GTP+CTP-treated peanuts were electrophoresed through $2 \%$ agarose gel, trans-blotted on to nylon membrane, followed by screening with ${ }^{32} \mathrm{P}$-labelled cDNA of the probe. The membrane was washed with low stringency solution and autoradiographed. Band $\{1\}$ is the mRNA encoding ABC transporter, and band $\{2\}$ is the mRNA encoding acid lipase.

Table 3. Effects of Nucleotide Solutions on the Abundance of mRNAs Encoding the Drug Metabolizing Enzymes. GDHSynthesized RNA Fragments were Used as Probes

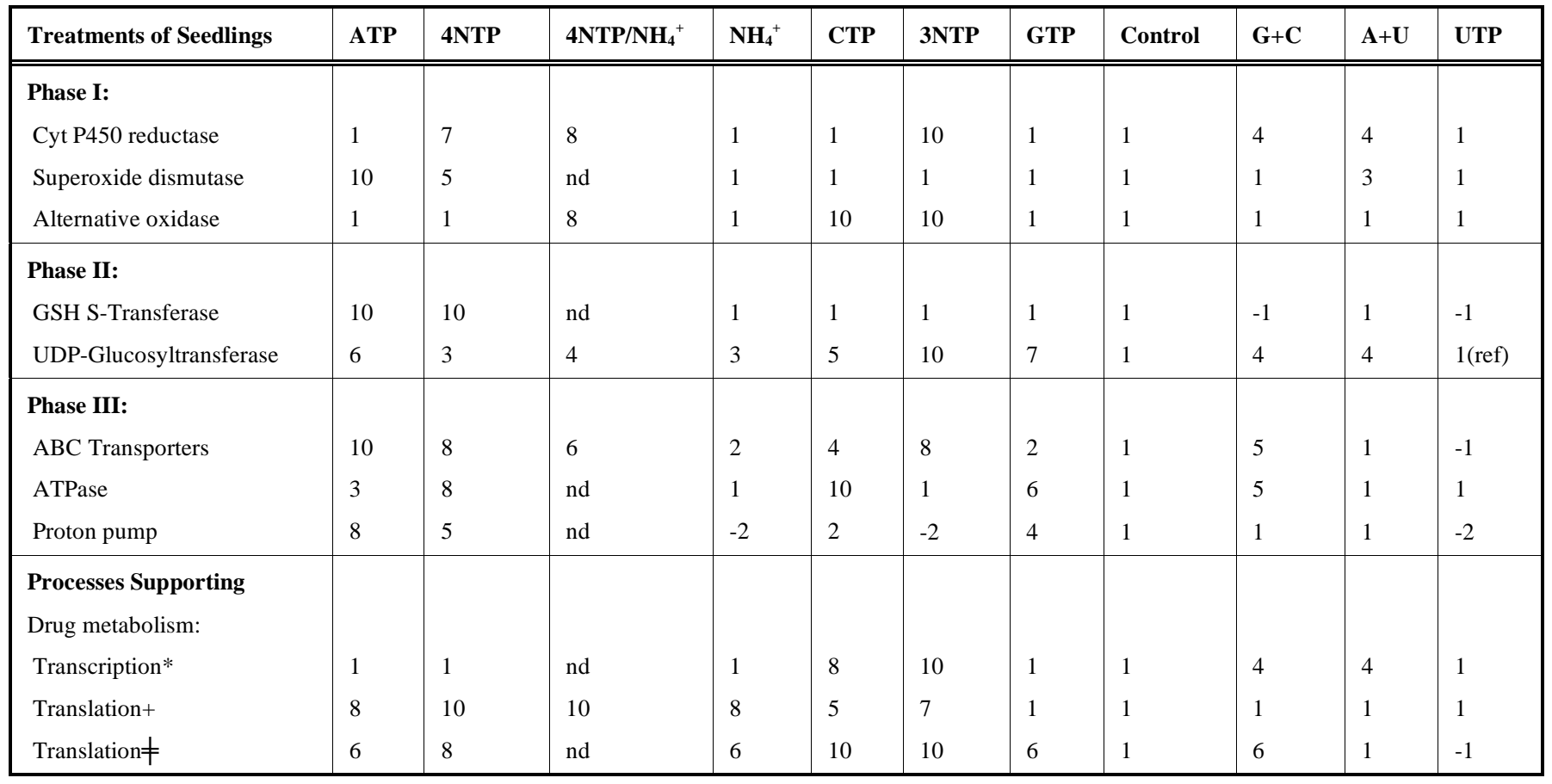

Notes: $n$ d is not determined; ref is [47].

*using fragment 2 as probe; + using fragment $3 \mathrm{a}$ as probe; $\neq$ using fragment 4 as probe. 
proton pump (Figure not shown). There were extensive sequence similarities between probes $5 \mathrm{a}$ and 6 (Table 1). Therefore, those drug treatments (4NTPs, ATP, and GTP) that upregulated the mRNA encoding ABC transporters also upregulated the abundance of those mRNAs encoding ATPase, and proton pump and vice versa thereby creating a coordinated reprogramming of the abundance of the mRNAs encoding the phase III enzymes. The reiterated sequence homologies between the GDH-synthesized RNA and the mRNAs encoding the drug metabolizing enzymes constituted further biochemical basis for their application as probes in drug screening assays.

As a general quality control for the probes and the total RNA used in the northern assays, fragment \#7, isolated from the total RNA lane on the differential display sequencing gel, and which shared sequence homology with $28 \mathrm{~S}$ rRNA, was used as a probe. All the treatments gave a single band, the $28 \mathrm{~S}$ rRNA (Fig. 6). The band was not smeared proving that the total RNA preparations were not degraded. Furthermore, fragment \#7 did not share sequence homology with any fragments used as probes thus proving that they were not rRNA in origin.

\section{Support of Drug Metabolism by Translation and Tran- scription}

GDH-synthesized RNA probe \#2 was homologous to the mRNA encoding homeobox protein (transcriptional factor) [67] in addition to the mRNA encoding SOD2 (Fig. 2). The abundance of the mRNA encoding the transcriptional factor was reciprocally reprogrammed with respect to the mRNA encoding SOD2 (Table 3). GDH-synthesized RNA probe \#3a was homologous to the mRNA encoding ribosomal proteins (translational factors) in addition to the mRNA encoding AOX2a (Fig. 3). But the abundance of the mRNA encoding AOX2a was upregulated or suppressed with the mRNA encoding the translational factors (Table 3). GDHsynthesized RNA probe \#4 was also homologous to the mRNA encoding some ribosomal proteins (translational factors) in addition to the mRNA encoding GST (Fig. 4). The abundance of the mRNA encoding the translational factors was reciprocally reprogrammed with respect to the mRNA encoding GST (Table 3). These results showed that drugs that downregulated the abundance of the mRNA encoding the transcriptional factor upregulated the mRNAs encoding the translational factors and vice versa. Therefore, translation and transcription supported the drug detoxication reactions; the reactions of the GDH-synthesized RNAs being part of the processes that connected drug metabolism, transcription and translation.

\section{Periodic Sequence Repeats}

The GDH-synthesized RNAs displayed internal molecular rhythms. In probe 5a (homologous to the mRNAs encod- ing $\mathrm{ABC}$ transporters and acid lipase), the repeating sequence rhythm (TGAGTCCTGACCGAGAACGGCATTGATAGCGA) was 32 nucleotides long, and it was repeated 13 times. The repeated sequence consisted of three segments (7, 16, and 9 nucleotides long) each of which was preceded by the trinucleotide TGA. This repeated periodicity of the three sections in the same sequential order, demonstrated the astounding fidelity of GDH in RNA synthesis. Also, the GDH-synthesized RNA \#4 that was homologous to the mRNAs encoding the flavonoid biosynthetic enzyme, ribosomal protein $\mathrm{S} 3$, and NADH dehydrogenase [23] consisted of 5 end-to-end repeats of the 32-nucleotide unit CGG CATTGATAGCGATGAGTCCTGACCGACAA. GDHsynthesized RNA \#1 that was homologous to the mRNA encoding acetyl-CoA carboxylase [44] was a 5.5 times endto-end rhythm of the 32-nucleotide unit GAGTCCTGACCGAGAACGGCATTGATAGCGAT. What could be the essence of the periodic end-to-end sequence repeats? GDH isoenzyme consists of six subunit polypeptides. The rhythmic sequence repeats may represent the stepwise cooperation in concert, of the GDH catalytic sites to synthesize the RNA. These end-to-end sequence repeats are the unique structural features of the GDH-synthesized RNAs, and constitute further evidence that the RNAs were not contaminants. GDHsynthesized RNAs regulated the abundance of several mRNAs. When the GDH-synthesized RNA downregulated the abundance of an mRNA, the concentration of the endproduct of the metabolic pathway or the enzyme activity was simultaneously decreased [23, 47, 66]. Therefore, there is direct cause-effect relationship in the mechanism of GDHsynthesized RNA. The repeating units in the GDHsynthesized RNAs may therefore be the convergent molecular rhythms that coordinate the metabolic pathways being controlled, and thereby linking gene expression, metabolism and the environment. The convergent periodicity of the repeats confirmed the potential utility of the RNA as genomic metabolic probe in drug metabolism research.

\section{DISCUSSION}

Results presented above showed that short (3-32 nucleotides) sequences in mRNAs were repeated many times in the sequences of GDH-synthesized RNAs. Such repeats also characterized the probes used for studying the reprogramming of mRNAs encoding the enzymes of fat and cellulose metabolic pathways $[47,66]$, and also of general metabolism [23]. Besides the control without any drug treatment, there were positive environmental controls $\left(\mathrm{NH}_{4} \mathrm{Cl}\right.$, chitosan, 4NTPs $+\mathrm{NH}_{4} \mathrm{Cl}$ ), and negative control probes (from total RNA) in the experimentation. The positive environmental controls were the best-documented biochemical regulators (inducers) of GDH isomerization [16, 66] their combined effects on the isomerization being synergistic or additive, but not antagnostic (Table 3) in the signal integration and discrimination functions of the enzyme [15]. Therefore, their

Table 4. Cytochrome P-450 and Superoxide Dismutase Activities ( $\mu \mathrm{mol}$ MTT min ${ }^{-1} \mathrm{mg}^{-1}$ Protein) of Extracts of Peanut Seedlings

\begin{tabular}{|c|c|c|c|c|c|c|c|c|c|}
\hline Treatments of Seedlings & ATP & 4NTP & CTP & 3NTP & GTP & Control & G+C & A+U & UTP \\
\hline \hline Cyt P450 & $3.3 \pm 0.4$ & $6.0 \pm 0.7$ & $3.37 \pm 0.4$ & $7.8 \pm 0.7$ & $3.9 \pm 0.4$ & $2.9 \pm 0.3$ & $3.3 \pm 0.2$ & $3.4 \pm 0.3$ & $2.6 \pm 0.3$ \\
\hline SOD & $2.1 \pm 0.2$ & $0.8 \pm 0.1$ & $0.3 \pm 0.01$ & $0.4 \pm 0.04$ & $0.5 \pm 0.02$ & $0.7 \pm 0.08$ & $0.9 \pm 0.1$ & $1.3 \pm 0.1$ & $0.5 \pm 0.04$ \\
\hline
\end{tabular}




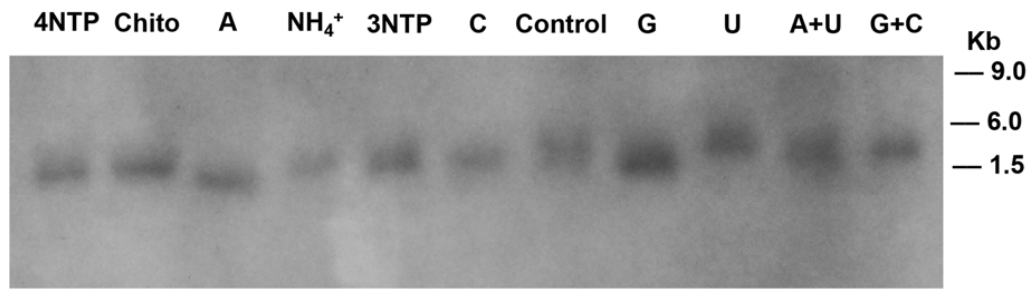

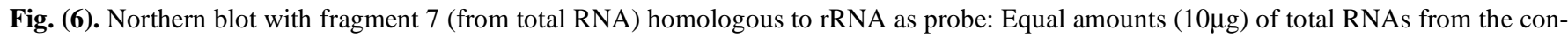
trol, and from 4NTPs, Chitosan, ATP, $\mathrm{NH}_{4} \mathrm{Cl}$, 3NTPs, CTP, GTP, UTP, ATP+UTP, GTP+CTP-treated peanuts were electrophoresed through $2 \%$ agarose gel, trans-blotted on to nylon membrane, followed by screening with ${ }^{32} \mathrm{P}$-labelled cDNA of the probe. The membrane was washed with low stringency solution and autoradiographed. The band is $28 \mathrm{~S}$ rRNA.

ability to reprogram the mRNA abundance relative to the untreated control was predictable based on the GDH isoenzyme population pattern they were known to induce [66]. From the GDH isoenzyme patterns induced by nucleoside triphosphates [66], the less positive the reduction potential of a nucleotide, the higher the number of GDH isoenzymes induced by the nucleotide, and the higher also was the probability that the abundance of the mRNAs encoding the drugmetabolizing enzymes would be upregulated, indicative of favorable pharmacokinetics. Conversely, the more positive the reduction potential of a nucleotide, the fewer the number of GDH isoenzymes induced, and the higher was the probability that the abundance of the mRNAs encoding the drugmetabolizing enzymes would be normal or downregulated, indicative of unfavorable pharmacokinetics. These relationships could serve as a model for predicting the pharmacokinetic properties of potential drug candidates at an early stage in drug development, and thus minimize costly clinical trials [68].

GDH-synthesized RNA probes gave higher hybridization signals as compared with homologous probes (negative controls) isolated from total RNA. Therefore, unlike the genetic code-based nucleic acid probes, GDH-synthesized RNAs (metabolism-based nucleic acid probes) are metabolically designed to interact optimally with mRNA targets by flipping around mRNA secondary structures. From the above results, the environment and the drug metabolism were connected by the isomerization of GDH. Also, the RNAs synthesized by the GDH isoenzymes connected mRNA abundance and drug metabolism. Therefore, gene expression, the environment (diseases) and the drug molecules were connected by the RNA synthetic activity of GDH. These genetic metabolic connections may now accelerate the pace of drug screening and discovery by increasing the application of microarray technique in the identification of the consortium of enzymes that may degrade a given drug (pharmacokinetics), the group of enzymes that may be suppressed by a given drug; and the explanation of adverse drug reactions, genetic polymorphisms in terms of changes in mRNA abundance; streamlined molecular screening of disease conditions, and simplification of gene expression data analysis. The results of the photometric assays of peanut enzyme activities proved that the SOD and CPR enzyme activities were present at the levels proportional to their respective encoding mRNAs as detected by the GDH-synthesized RNA probes. These results on peanut CPR, SOD, AOX, GSH S-transferase, UDPglucosyltransferase, ABC transporters, etc suggest that plants could be excellent organisms for the environment-wide screening of potential drug candidates thereby minimizing the cost of drug discovery research. The huge volume and multi-dimensionality of data derived from genome-wide expression analysis using genetic code-based nucleic acid probes may not be amenable to statistical tools of analyses because of the incompleteness of such hybridization reactions [69]. Since GDH is a mitochondrial enzyme present in eukaryotic organisms, and it integrates and discriminates metabolic signals, the application of the GDH-synthesized RNA probes in drug metabolism research has wide potentials.

\section{CONCLUSION}

Administered nucleotides induced changes in the isomerization and RNA synthetic activity of GDH. Northern analysis using the GDH-synthesized RNAs as probes showed that the administration of ATP induced the maximum upregulation of the mRNAs encoding SOD2, GST, and ABC transporters; administration of CTP upregulated the abundance of the mRNAs encoding GST, AOX2a, proton pump, and ABC transporters; whereas administration of GTP and UTP similar to the untreated control did not induce the upregulation of the drug-metabolizing enzymes. But the 3NTPs mix (ATP + UTP + GTP) upregulated the mRNAs encoding CPR, AOX2a, and UDP-glucosyl transferase. GDH-synthesized RNA probes gave higher hybridization signals than the homologous genetic code-based probes thus suggesting that the former could interact strongly with their mRNA targets despite secondary structures in the mRNA. Photometric assays confirmed that the CPR and SOD enzyme activities were proportional to the mRNA levels detected by the GDH-synthesized RNAs. Therefore, the GDHsynthesized RNAs were specific probes for studying drug metabolism. All the enzymes studied are important in preclinical pharmacokinetic studies. The GDH-synthesized RNAs displayed internal periodic sequence repeats. The RNAs that were homologous to the mRNAs encoding the drug-metabolizing enzymes shared extensive sequence similarities. Therefore, the environment, gene expression, and drug metabolism were linked by GDH. These metabolic genetic connections could diversify and accelerate the pace of probe preparation, drug screening, and drug discovery. 


\section{ACKNOWLEDGEMENT}

This research project was supported in part through grants made by Texas Agricultural Experiment Station to Prairie View A\&M University.

\section{REFERENCES}

[1] Ortiz de Montellano, P.R. Cytochrome P450: Structure, Mechanism, and Biochemistry, $3^{\text {rd }}$ ed.; Kluwer Academic/Plenum Press: New York, 2005.

[2] Raucy, J.L.; Allen, S.W. Recent advances in P450 research. Pharmacogenom. J., 2001, 1 (3), 178-186.

[3] Xu, C.; Li, C.Y.; Kong, A.N. Induction of phase I, II and III drug metabolism/transport by xenobiotics. Arch. Pharm. Res., 2005, 28, 249-268.

[4] Lesh, L.H. Drug metabolism and transport. Humana Press Inc.: Totowa, NJ, 2005

[5] Gerhold, D.; Lu, M.; Xu, J.; Austin, C.; Caskey, C.T.; Rushmore, T. Monitoring expression of genes involved in drug metabolism and toxicology using DNA microarrays. Physiol. Genom., 2001, 5, $161-170$.

[6] Elfarra, A.A. In Drug metabolism and transport; Lesh, L.H. Ed.; Humana Press Inc.: Totowa, NJ, 2005; pp. 1-18.

[7] Zimmermann, H. Extracellular metabolism of ATP and other nucleotides. Naunyn-Schmiedeberg's Arch. Pharmacol., 2000, 362, 299-309.

[8] Regnier, M.; Lee, D.M.; Homsher, E. ATP analogs and muscle contraction: Mechanics and kinetics of nucleoside triphosphate binding and hydrolysis. Biophys. J., 1998, 74, 3044-3058.

[9] Weinsein, J.N.; Pommier, P. Connecting genes, drugs and diseases. Nat. Biotechnol., 2006, 24 (11), 1365-1366.

[10] Park, B.K.; Kitteringham, N.R.; Kenny, J.R.; Pirmohamed, M. Drug metabolism and drug toxicity. Inflammopharmacology, 2001, 9(1,2), 183-199.

[11] Hu, G.; Modrek, B.; Stensland, H.M.F.R.; Saarela, J.; Pajukanta, P.; Kustanovich, V.; Peltonen, P.; Nelson, S.F.; Lee, C. Efficient discovery of single-nucleotide polymorphisms in coding regions of human genes. Pharcogenom. J., 2002, 2, 236-242.

[12] Osuji, G.O.; Konan, K.; M'Mbijjewe, G. RNA synthetic activity of glutamate dehydrogenase. Appl. Biochem. Biotechnol., 2004, 119, 209-228.

[13] Osuji, G.O.; Haby, V.A.; Chessman, D.J. Metabolic responses induced by serial harvesting of alfalfa pasture established on amended acid soil. Comm. Soil Sci. Plant Anal., 2006, 37, 12811301.

[14] Brown, A.; Culver, J.M.; Fisher, H.F. Mechanism of inactivation of L-glutamate dehydrogenase by pyridoxal and pyridoxal phosphate. Biochemistry, 1973, 12, 4367-4374.

[15] Osuji, G.O.; Braithwaite, C. Signaling by glutamate dehydrogenase in response to pesticide treatment and nitrogen fertilization of peanut. J. Agric. Food Chem., 1999, 47, 3332-3344.

[16] Osuji, G.O.; Braithwaite, C.; Fordjour, K.; Madu, W.C.; Beyene, A.; Roberts, P.S.; Wright, V. Purification of glutamate dehydrogenase isoenzymes and characterization of their substrate specificities. Prep. Biochem. Biotechnol., 2003., 33, 13-28.

[17] Osuji, G.O.; Braithwaite, C.; Pointer, R.; Reyes, J. Pesticide inactivation of peanut glutamate dehydrogenase: Biochemical basis of the enzyme's isomerization. Agric. Food Chem., 1999, 47, 33453351.

[18] Morris, A.J.; Tolan, D.R. Site-directed mutagenesis identifies aspartate 33 as a previously unidentified critical residue in the catalytic mechanism of rabbit aldolase A. J. Biol. Chem., 1993, 268, 1095-1100.

[19] Highbarger, L.A.; Gertt, J.A.; Kenyon, G.L. Mechanism of the reaction catalyzed by acetoacetate decarboxylase. Importance of lysine 116 in determining pKa of active lysine 115. Biochemistry, 1996, 35, 41-46.

[20] Nandi, D.L.; Shermin, D. $\delta$-Aminolevulinic acid dehydratase of Rhodopseudomonas spheroids III. Mechanism of porphobilinogen synthesis. J. Biol. Chem., 1968, 243, 1236-1242.

[21] Nash, H.M.; Bruner, S.D.; Sharer, O.D.; Kawate, T.; Addona, T.A.; Spooner, E.; Lane, W.; Verdine, G.L. Cloning of a yeast 8oxoguanine DNA glycosylase reveals the existence of a baseexcision DNA-repair protein superfamily. Curr. Biol., 1996, 6, 968-980.
Rabeh, W.M.; Cook, P.F. Structure and mechanism of Oacetylserine sulfhydrylase. J. Biol. Chem., 2004, 279, 2680326806.

[23] Osuji, G.O.; Brown, T. Role of the RNAs synthesized by glutamate dehydrogenase in the coordinate regulation of metabolic process. Icfai J. Biotechnol., 2007, 1(3), 37-48.

[24] Khomyakova, E.; Livshits, M.A.; Steinhauser, M.; Dauphinot, L.; Cohen-Kaminsky, S.; Rossier, J.; Soussaline, F.; Potier, M. Onchip hybridization kinetics for optimization of gene expression experiments. Biotechniques, 2008, 44, 109-117.

[25] Lauterburg, B.H. In Drug metabolism and transport; Lesh, L.H. Ed.; Humana Press Inc., Totowa, NJ, 2005; pp. 233-251.

[26] Jarmuszkiewicz, W.; Behrendt, M.; Navet, R.; Sluse, F.E. Uncoupling protein and alternative oxidase of Dictyostelium discoideum: Occurrence properties and protein expression during vegetative life and starvation-induced early development. FEBS Lett., 2002, 532, 459-464.

[27] Grierson, D.; Slater, A.; Speirs, J.; Tucker, G.A. The appearance of polygalacturonase mRNA in tomatoes. Planta, 1985, 163, 263-271.

[28] Yim, S.; Yun, C.; Ahn, T.; Jung, H.; Pan, J. A continuous spectrophotometric assay for NADPH-cytochrome P450 reductase activity using 3-(4,5-dimethylthiazol-2-yl)-2,5-diphenyltetrazolium bromide. J. Biochem. Mol. Biol., 2005, 38, 366-369.

[29] McCord, J.M.; Fridovich, I. Superoxide dismutase: An enzymatic function for erythrocuprein (chemocuprein). J. Biol. Chem., 1969, 244, 6049-6055.

[30] Prochaska, H.J. Purification and crystallization of rat liver NADP $(\mathrm{H})$ quinone-acceptor oxidoreductase by cibacorn blue affinity chromatography. Identification of new and potent inhibitor. Arch. Biochem. Biophys., 1988, 267, 529-538.

[31] Cammaerts, D.; Jacobs, M. A study of the polymorphism and the genetic control of the glutamate dehydrogenase isoenzymes in Arabidopsis thaliana. Plant Sci. Lett., 1983, 31, 65-73.

[32] Cammaerts, D.; Jacobs, M. A study of the role of glutamate dehydrogenase in the nitrogen metabolism of Arabidopsis thaliana. Planta, 1985, 163, 517-526.

[33] Loulakakis, K.A.; Roubelakis-Angelakis, K.A. The seven $\mathrm{NAD}(\mathrm{H})$-glutamate dehydrogenase isoenzymes exhibit similar anabolic and catabolic activities. Physiol. Plant, 1996, 96, 29-35.

[34] Tatusova, T.; Madden, T.L. Blast 2 sequence- A new tool for comparing protein and nucleotide sequences. FEMS Microbiol. Lett., 1999, 174, 247-250.

[35] West, S.M.; Price, N.C. The unfolding and refolding of glutamate dehydrogenase from bovine, baker's yeast and Clostridium symbosium. Biochem. J., 1988, 251, 135-139.

[36] Osuji, G.O.; Haby, V.A.; Chessman, D.J.; Leonard, A.T. Responses of the fructose-1,6-bisphosphatase and glutamate dehydrogenase activities to boron, gypsum, and limestone amendments of soil. Photosynthetica, 2004, 42, 307-312.

[37] Osuji, G.O.; Madu, W.C.; Braithwaite, C.; Beyene, A.; Roberts, P.S.; Bulgin, A.; Wright, V. Nucleotide-dependent isomerization of glutamate dehydrogenase in relation to total RNA contents of peanut. Biol. Plant, 2003/4, 47, 195-202.

[38] Shet, M.S. Relevance of cytochrome P450s in plants: Also one of Ron Estabrook's research interests. Drug Metab. Rev., 2007, 39, 273-280.

[39] Correia, M.A.; Ortiz de Montellano, P.R. In Cytochrome P450s: Structure, Mechanism, and Biochemistry, 3rd ed.; Ortiz de Montellano, P.R., Eds.; Kluwer Academic/Plenum Publishers, New York, 2005. pp. 247-322.

[40] White, R.E.; Coon, M.J. Oxygen activation by cytochrome P-450. Ann. Rev. Biochem., 1980, 49, 315-356.

[41] Mizutani, M.; Ohta, D. Two isoforms of NADPH:cytochromr P450 reductase in Arabidopsis thaliana. Plant Physiol., 1998, 116, 357367.

[42] Ingelman-Sundberg, M. Implications of polymorphic cytochrome P450-dependent drug metabolism for drug development. DMD, 2001, 29, 570-573

[43] Trubetskoy, O.V.; Gibson, J.R.; Marks, B.D. Highly miniaturized formats for in vitro drug metabolism assays using vivid fluorescent substrates and recombinant human cytochrome P450 enzymes. $J$. Biomol. Screen., 2005, 10, 56-66.

[44] O'Leary, K.A.; McQuiddy, P.; Kasper, C.B. Transcriptional regulation of the TATA-less NADPH cytochrome P-450 oxidoreductase gene. Arch. Biochem. Biophys., 1996, 330, 271-280. 
[45] Taira, Y.; Greenspan, P.; Kapke, G.F.; Redick, J.A.; Baron, J. Effects of Phenobarbital, pregnenolone-16 $\alpha$-carbonitrile, and 3methylcholanthrene pretreatment on the distribution of NADPHcytochrome c(P-450) reductase within the liver lobule. J. Mol. Pharmacol., 1980, 18, 304-312.

[46] Tanaka, M.; Takei, K.; Kojima, M.; Sakakibara, H.; Mori, H. Auxin controls cytokinin biosynthesis in the nodal stem in apical dominance. Plant J., 2006, 6, 1028-1036.

[47] Osuji, G.O.; Brown, T. Environment-wide reprogramming of mRNAs encoding phosphate translocator and glucosyltransferase in relation to cellulosic biomass accumulation in peanut. Icfai J. Biotechnol., 2007, 1 (4), 35-47.

[48] Shina, S.; Lee, H.; Kwon, S.; Kwon, S.; Kwak, S. Molecular characterization of a cDNA encoding copper/zinc superoxide dismutase from cultured cells of Manihot esculenta. Plant Physiol. Biochem., $\mathbf{2 0 0 5}, 43,55-60$

[49] Malmstrom, B.; Andreasson, L.; Reinhammer, B. The Enzymes, $3^{\text {rd }}$ ed.; Boyer, P., Eds.; Academic Press, New York, 1975; Vol. 12,

[50] Forman, H.J.; Fridovich, I. Superoxide dismutase: a comparison of rate constants. Arch. Biochem. Biophys., 1973, 158, 396-400.

[51] Fridovich, I. The biology of oxygen radicals. Science, 1978, 201, 875-880.

[52] Boom, W.J.; Auwarter, K.E.; Ni, J.; Russel, D.E.; Yeh, L.A.; Maxwell, M.M.; Glicksman, M.; Kazantsev, A.G.; Brown, R.H. Two approaches to drug discovery in SOD1-mediated ALS. $J$. Biomol. Screen., 2006, 11, 729-735.

[53] Hekstra, D.; Taussig, A.R.; Magnasco, M.; Naef, F. Absolute mRNA concentrations from sequence-specific calibration of oligonucleotide arrays. Nucleic Acids Res., 2003, 31, 1962-1968.

[54] McDonald, A.; Vanlerberghe, G. Branched mitochondrial electron transport in the animalia: Presence of alternative oxidase in several animal phyla. IUBMB Life, 2004, 56, 333-341.

[55] Hakkaart, G.A.J.; Dassa, E.P.; Jacobs, H.T.; Rustin, P. Allotropic expression of mitochondrial alternative oxidase confers cyanide resistance to human cell respiration. EMBO Rep., 2006, 7, 341-345.

[56] Ando, K.; Homa, M.; Chiba, S.; Tahara, S.; Mizutani, J. Glutathione transferase from Mucor javanicus. Agric. Biol. Chem., 1988, 52, 135-139.

[57] Houston, D.H. In Bound and Conjugated Pesticide Residues; Kaufman, D.D.; Still, G.G.; Paulson, G.D.; Bandal, S.K., Ed.; American Chemical Society, Washington, D.C., 1976; pp. 103-131

[58] McGonigle, B.; Keeler, S.J.; Lau, S.M.; Koeppe, M.K.; O'Keefe, D.P. A genomics approach to the comprehensive analysis of the glutathione S-transferase gene family in soybean and maize. Plant Physiol., 2000, 124 (3), 1105-1120.

[59] Morgenstern, R.; Depierre, J.W.; Ernster, L. Activation of microsomal glutathione S-transferase activity by sulfhydryl reagents. Biochem. Biophys. Res. Commun., 1979, 87, 657-663.

[60] Ates, N.A.; Tursen, U.; Tamer, L. Glutathione S-transferase polymorphisms in patients with drug eruption. Arch. Dermatol. Res. 2004, 295, 429-433.

[61] Van den Brule, S.; Muller, A.; Fleming, A.J.; Smart, C.C. The ABC transporter SpTUR2 confers resistance to the antifungal diterpene sclareol. Plant J., 2002, 30 (6), 649-662.

[62] Dean, M.; Rzhetsky, A.; Allikmets, R. The human ATP-binding cassette (ABC) transporter superfamily. Genome Res., 2001, 11 1156-1166.

[63] Sheps, J.A.; Ralph, S.; Zhao, Z.; Baillie, D.L.; Ling, V. The ABC transporter gene family of Caenorhabditis elegans has implications for the evolutionary dynamics of multidrug resistance in eukaryotes. Genome Biol., 2004, 5, R15.

[64] Doyle, L.A.; Yang, W.; Abruzzo, L.V.; Krogmann, T.; Gao, Y.; Rishi, A. K.; Ross, D.D. A multidrug resistance transporter from human MCF-7 breast cancer cells. Proc. Natl. Acad. Sci. USA, 1998, 95, 15665-15670.

[65] Maliepaard, M.; van Gastelen, M. A.; de Jong, L.A.; Pluim, D.; van Waardenburg, R.C.; Ruevekamp-Helmers, M. C.; Floot, B. G.; Schellens, J. H. Overexpression of the BCRP/MXP/ABCP gene in a topotecan-selected ovarian tumor cell line. Cancer Res., 1999, 59, 4559-4563.

[66] Osuji, G.O.; Brown, T.; South, S. Environment-wide reprogramming of mRNAs encoding acetyl coenzyme A carboxylase and lipoxygenase in relation to the fat contents of peanut. SAAS Bull. Biochem. Biotechnol., 2008. (accepted for publication).

[67] Morimoto, R.; Kosugi, T.; Nakamura, C.; Takumi, S. Intragenic diversity and functional conservation of the three homeologous loci of the KN1-type homeobox gene Wknox1 in common wheat. Plant Mol. Biol., 2005, 57(6), 907-924.

[68] Monro, A.M. In The Use of Human In Vitro Systems to Support Preclinical and Clinical Safety Assessment; Sundwall, A.; Alvan, G.; Lindgren, E., Moldeus, M., Eds. The Swedish Association of the Pharmaceutical Industry and Medical Products Agency, Stockholm, Sweden, 1996; pp. 1-4.

[69] Clarke, R.; Ressom, H.R.; Wang, A.; Xuan, J.; Liu, M.C.; Gehan, E.A.; Wang, Y. The properties of high-dimensional data spaces: Implications for exploring gene and protein expression data. Nat. Rev. Cancer, 2008, 8, 37-49.

Received: May 30, 2008

(C) Osuji et al.; Licensee Bentham Open.

This is an open access article licensed under the terms of the Creative Commons Attribution Non-Commercial License (http://creativecommons.org/licenses/by-nc/3.0/) which permits unrestricted, non-commercial use, distribution and reproduction in any medium, provided the work is properly cited. 